\title{
Digestibilidade aparente de farelos vegetais tratados para remoção de antinutrientes em dietas para jundiá
}

\author{
Giovani Taffarel Bergamin ${ }^{(1)}$, Cátia Aline Veiverberg ${ }^{(3)}$, Luciana Valentim Siqueira(2), \\ Daniel Prois Eggers ${ }^{(2)}$ e João Radünz Neto ${ }^{(2)}$
}

\begin{abstract}
(1)Embrapa Pesca e Aquicultura, Quadra 103 Sul, Avenida JK, ACSO 1, Conjunto 1, Lote 17, 10 piso, CEP 77015-012 Palmas, TO. E-mail: giovani.bergamin@embrapa.br (2)Universidade Federal de Santa Maria, Departamento de Zootecnia, Laboratório de Piscicultura, Avenida Roraima, no 1.000, Camobi, CEP 97105-900 Santa Maria, RS. E-mail: luciana.siqueira@zootecnista.com.br, prois89@gmail.com, jradunzneto@gmail.com ${ }^{(3)}$ Instituto Federal Farroupilha, Campus Júlio de Castilhos, Rodovia RS-527, Estrada de Acesso Secundário a Tupanciretã, Distrito de São João do Barro Preto, CEP 98130-000 Júlio de Castilhos, RS. E-mail: catiaveiver@yahoo.com.br
\end{abstract}

Resumo - O objetivo deste trabalho foi avaliar a digestibilidade aparente de farelos vegetais, submetidos ou não a tratamento químico para extração de antinutrientes, em dietas para jundiá (Rhamdia quelen). Foram formuladas três dietas-teste com fontes proteicas na forma comercial sem tratamento - SNT, farelo de soja; CNT, farelo de canola; e GNT, farelo de girassol - e três dietas submetidas a tratamento para redução de ácido fítico, fenóis totais e taninos totais: ST, farelo de soja tratado; CT, farelo de canola tratado; e GT, farelo de girassol tratado. Os tratamentos CNT, CT, GNT e GT apresentaram menor digestibilidade aparente da matéria seca. O tratamento ST apresentou maior digestibilidade da proteína bruta que CT e CNT, mas não diferiu dos demais tratamentos. Os tratamentos GNT, GT e CNT apresentaram as menores digestibilidades da matéria orgânica. A remoção de antinutrientes não afeta a digestibilidade aparente de proteína bruta, matéria seca e matéria orgânica dos farelos de soja e girassol, mas melhora a digestibilidade da matéria seca do farelo de canola.

Termos para indexação: Rhamdia quelen, farelo de canola, farelo de girassol, farelo de soja, fatores antinutricionais, piscicultura.

\section{Apparent digestibility of plant meal subjected to antinutrient removal in diets for South American catfish}

\begin{abstract}
The objective of this work was to evaluate the apparent digestibility of plant-protein meals, subjected or not to antinutrient extraction chemical treatment, in diets for South American catfish (Rhamdia quelen). Three test diets were formulated with protein sources in commercial form without treatment - SNT, soybean meal; CNT, canola meal; and GNT, sunflower meal - and three diets were subjected to treatment for reduction of phytic acid, total phenols, and tannins: ST, treated soybean meal; CT, treated canola meal; and GT, treated sunflower meal. The treatments CNT, CT, GNT, and GT had lower dry matter apparent digestibility. The treatment ST had higher crude protein digestibility than CT and CNT, but it did not differ from the other treatments. GNT, GT, and CNT treatments showed the lowest organic matter digestibility. Antinutrient removal does not affect the apparent digestibility of crude protein, dry matter, and organic matter of soybean and sunflower meal, but improves the dry matter digestibility of canola meal.
\end{abstract}

Index terms: Rhamdia quelen, canola meal, sunflower meal, soybean meal, antinutritional factors, fish culture.

\section{Introdução}

A farinha de peixe é a fonte de proteína mais utilizada na formulação de rações para peixes, por seu adequado conteúdo de aminoácidos essenciais, por não conter fatores antinutricionais e por apresentar alta digestibilidade e palatabilidade (Naylor et al., 2000; Gatlin III et al., 2007; Kaushik \& Seiliez, 2010). Porém, em razão do alto custo de aquisição de farinha de peixe de qualidade e da diminuição da disponibilidade deste ingrediente para a aquicultura, principalmente pela redução dos estoques pesqueiros e dos impactos ecológicos e sociais da sobrepesca, busca-se a substituição dessa fonte proteica por outras de menor custo, mas que assegurem desempenho zootécnico favorável (Naylor et al., 2000; Organización de las Naciones Unidas para la Agricultura y la Alimentación, 2012).

As fontes proteicas de origem vegetal são, em geral, mais baratas e disponíveis em maior quantidade que a 
farinha de peixe. No Brasil, a soja, a canola e o girassol têm sido cultivados em grande escala em decorrência de seu potencial para a produção de óleo comestível e combustível (Silva \& Freitas, 2008), o que tem aumentado a disponibilidade de farelos dessas culturas. Entretanto, a utilização de ingredientes vegetais é limitada pela presença de substâncias antinutricionais, que podem agir de forma direta, ou por meio de seus produtos metabólicos, na utilização do alimento pelos animais (Francis et al., 2001). A extração ou inativação de compostos antinutricionais presentes nesses ingredientes pode gerar concentrados proteicos de alto valor nutricional.

Adeterminação da digestibilidade quantifica a fração do nutriente não excretada nas fezes (Oliveira Filho \& Fracalossi, 2006). A digestibilidade de um ingrediente ou de uma dieta depende de características da espécie em estudo, como hábito alimentar, anatomia do sistema digestivo e metabolismo, além de características dos ingredientes, como origem (animal ou vegetal) e processamento (Cho \& Bureau, 2001). Quanto maior o coeficiente de digestibilidade do alimento, maior será o seu aproveitamento pelos animais, com reflexos positivos nos índices produtivos. Alimentos altamente digestíveis contribuem também para a diminuição da excreção de nutrientes no ambiente de cultivo (Oliveira Filho \& Fracalossi, 2006).

O jundiá (Rhamdia quelen), espécie nativa cultivada na Região Sul do Brasil, aproveita melhor os alimentos ricos em proteína do que os ricos em energia. Tal comportamento se assemelha ao de alguns peixes onívoros e, principalmente, ao de carnívoros, o que o torna um peixe de hábito alimentar onívoro, com tendência à carnivoria (Oliveira Filho \& Fracalossi, 2006). Contudo, o jundiá não depende totalmente da farinha de peixe da dieta, pois aceita dietas exclusivamente vegetais ou compostas de vegetais com farinhas de origem animal (Coldebella \& Radünz Neto, 2002; Lazzari et al., 2008).

O objetivo deste trabalho foi avaliar a digestibilidade aparente de farelos vegetais, submetidos ou não a tratamento químico para extração de antinutrientes, em dietas para jundiá (Rhamdia quelen).

\section{Material e Métodos}

O experimento foi realizado no Laboratório de Piscicultura da Universidade Federal de Santa Maria, de janeiro a abril de 2012. Foram avaliadas três dietas-teste formuladas com fontes proteicas não submetidas a tratamento - SNT, farelo de soja não tratado; CNT, farelo de canola não tratado; e GNT, farelo de girassol não tratado - e três submetidas a tratamento para redução de ácido fítico, fenóis totais e taninos totais: ST, farelo de soja tratado; CT, farelo de canola tratado; e GT, farelo de girassol tratado. Utilizou-se o delineamento experimental inteiramente casualizado, com seis tratamentos e cinco repetições.

Para a retirada dos fatores antinutricionais, os farelos de girassol, canola e soja foram imersos e agitados em solução ácida e em etanol. Na primeira fase do tratamento (imersão em solução ácida), $400 \mathrm{~g}$ de farelo foram misturados a $4 \mathrm{~L}$ de água destilada a $\mathrm{pH} 1,0$. Para ajuste do $\mathrm{pH}$ da água, foi utilizado ácido sulfúrico concentrado (98\%). A mistura foi acondicionada em recipientes de plástico com $5 \mathrm{~L}$ de volume útil, e submetida à agitação por uma hora em mesa agitadora (240 movimentos por minuto). Após a agitação, a mistura foi filtrada em peneira de $100 \mu \mathrm{m}$, de forma que o farelo ficasse o mais seco possível. O líquido resultante foi novamente filtrado em peneira de $25 \mu \mathrm{m}$. O material sólido recuperado na segunda peneira foi novamente adicionado à massa úmida de farelo. O líquido proveniente da filtragem em peneira de $25 \mu \mathrm{m}$ foi recolhido para precipitação e recuperação da proteína solubilizada. Para tal, o pH do líquido foi corrigido para 9,0, com hidróxido de sódio $1 \mathrm{~N}$, e logo após reduzido a 4,5, com ácido clorídrico $0,325 \mathrm{~N}$. Após o ajuste do $\mathrm{pH}$, o líquido ficou em repouso para precipitação da proteína. O sobrenadante foi descartado, e a proteína solubilizada foi centrifugada a $1.327 \mathrm{~g}$ por $5 \mathrm{~min}$. Novamente, o sobrenadante foi descartado para recuperar a fração sólida.

$\mathrm{Na}$ segunda fase, o farelo proveniente do tratamento ácido foi submetido a tratamento com álcool etílico comercial a $96^{\circ}$, em um recipiente com $5 \mathrm{~L}$ de volume útil. Foram adicionados $3 \mathrm{~L}$ de álcool etílico e a mistura foi submetida novamente à agitação por uma hora. Após esta etapa, o pH da mistura (farelo + álcool etílico) foi ajustado para 7,0, com hidróxido de sódio $1 \mathrm{~N}$. Assim como no tratamento ácido, o farelo foi filtrado em peneira de $100 \mu \mathrm{m}$ e $25 \mu \mathrm{m}$ e o $\mathrm{pH}$ do líquido resultante da filtragem, foi ajustado da mesma forma que anteriormente. A precipitação e a recuperação da proteína solubilizada também seguiram os mesmos procedimentos. Após a segunda filtragem, o farelo retido nas peneiras, bem como a proteína 
solubilizada recuperada, permaneceu em estufa de circulação forçada de ar a $60^{\circ} \mathrm{C}$ por 24 horas.

A composição dos ingredientes tratados e não tratados foi analisada e encontra-se na Tabela 1 . Os teores de proteína bruta (micro-Kjeldhal) foram determinados de acordo com o método 960.52 da AOAC International (Cuniff, 1995); a matéria seca foi determinada por permanência da amostra em estufa $\left(105^{\circ} \mathrm{C}\right)$ até a obtenção de massa constante; e a matéria mineral foi quantificada por queima a $550^{\circ} \mathrm{C}$, conforme o método 923.03 da AOAC International (Cuniff, 1995). O conteúdo de fibra em detergente neutro foi determinado com a metodologia proposta por Van Soest (1967), e os carboidratos digestíveis foram estimados por diferença.

Para realizar o ensaio de digestibilidade in vivo, foi utilizado o sistema Guelph adaptado (Cho et al., 1985), com cinco incubadoras de fibra de vidro tipo Zoug, com capacidade de 200 L cada, conectadas a um sistema de recirculação de água com temperatura controlada e filtragem biológica. Na parte inferior de cada incubadora, foram instalados registros de esfera,

Tabela 1. Composição dos farelos tratados e não tratados.

\begin{tabular}{lcccccc}
\hline Constituinte (\%) & \multicolumn{7}{c}{ Ingredientes $^{(1)}$} \\
\cline { 2 - 7 } & CNT & CT & GNT & GT & SNT & ST \\
\hline Matéria seca & 87,92 & 94,69 & 88,07 & 89,04 & 86,95 & 96,79 \\
Proteína bruta & 38,24 & 43,81 & 37,1 & 36,35 & 47,43 & 58,23 \\
Matéria mineral & 7,29 & 11,81 & 9,57 & 11,95 & 6,52 & 11,04 \\
Gordura & 3,46 & 1,12 & 1,55 & 0,72 & 3,49 & 2,16 \\
Fibra total & 32,57 & 37,72 & 33,26 & 38,36 & 21,64 & 25,62 \\
Carboidratos não fibrosos ${ }^{(2)}$ & 6,36 & 0,23 & 6,59 & 1,66 & 7,87 & - \\
Energia digestível $\left({\left.\mathrm{kcal} \mathrm{kg}^{-1}\right)^{(3)}}^{23}\right.$ & 2351 & 2319 & 2144 & 1937 & 2851 & 3130 \\
Lisina & 1,39 & 3,26 & 1,25 & 1,47 & 2,46 & 4,98 \\
Metionina+cistina & 1,39 & 1,77 & 1,09 & 0,92 & 1,16 & 1,02 \\
Arginina & 1,70 & 3,34 & 2,55 & 3,50 & 3,16 & 4,85 \\
Histidina & 0,81 & 1,51 & 0,81 & 1,28 & 1,05 & 1,99 \\
Isoleucina & 1,24 & 2,13 & 1,30 & 1,84 & 1,95 & 3,04 \\
Leucina & 2,20 & 3,61 & 2,24 & 2,83 & 3,23 & 4,64 \\
Fenilalanina & 1,20 & 2,06 & 1,41 & 2,12 & 2,13 & 3,19 \\
Treonina & 1,24 & 2,04 & 1,15 & 1,55 & 1,63 & 2,36 \\
Valina & 1,66 & 2,62 & 1,64 & 2,15 & 2,08 & 3,27 \\
Triptofano & 0,39 & - & 0,46 & - & 0,61 & - \\
Ácido fítico & 1,95 & 1,88 & 3,07 & 2,26 & 1,02 & 1,53 \\
Fenóis totais & 1,81 & 0,24 & 3,15 & 0,36 & 0,67 & 0,16 \\
Taninos totais & 1,10 & 0,10 & 2,23 & 0,23 & 0,53 & 0,05 \\
\hline
\end{tabular}

${ }^{(1)} \mathrm{CNT}$, farelo de canola não tratado; CT, farelo de canola tratado; GNT, farelo de girassol não tratado; GT, farelo de girassol tratado; SNT, farelo de soja não tratado; ST, farelo de soja tratado. ${ }^{(2)}$ Calculado segundo a fórmula $\mathrm{CNF}=\% \mathrm{MS}-(\% \mathrm{~PB}+\%$ Gordura $+\% \mathrm{FT}+\% \mathrm{MM}) .{ }^{(3)} \mathrm{Calculada}$ segundo a equação $\mathrm{ED}=[(\% \mathrm{~PB} \times 5,64 \times 0,90)+(\%$ Gordura $\times 9,51 \times 0,85)+(\mathrm{CNF}$ $\times 4,11 \times 0,50)] 10$ (Jobling, 1983). adaptados para o acoplamento de tubos tipo Falcon, utilizados na coleta das fezes. Os tubos ficavam imersos em recipientes com gelo, para minimizar a degradação das fezes por ação bacteriana. Para a coleta, o registro era fechado, e o tubo retirado. Na porção intermediária das incubadoras, foi colocada uma tela para evitar o acesso dos peixes às fezes depositadas no fundo.

Em cada incubadora, foram estocados 22 juvenis de jundiá. Do início ao final do período experimental, a biomassa total média variou de 688,2 a 840 g por incubadora. A qualidade da água foi monitorada diariamente, quanto à temperatura, e, semanalmente quanto a oxigênio dissolvido, $\mathrm{pH}$, amônia total, nitrito, alcalinidade e dureza total, e manteve-se dentro dos limites ideais para a espécie durante todo o período (Baldisserotto \& Silva, 2005).

Para a determinação da digestibilidade dos ingredientes avaliados, utilizou-se uma dieta-referência à base de farinha de peixe. As dietas-teste consistiram de $69,94 \%$ da dieta-referência e $30 \%$ do ingrediente da avaliação (Tabela 2). Todas as dietas continham $0,2 \%$ de óxido de cromo III, utilizado como marcador inerte. Para a coleta de fezes de cada uma das dietas, os peixes das cinco incubadoras foram alimentados com a mesma dieta pelo período de três dias, para adaptação, tendose iniciado, então, o período de coleta, que perdurou até a obtenção de, no mínimo, $30 \mathrm{~g}$ de fezes úmidas por incubadora.

As fezes eram coletadas às 8:00 e às 17:00 h. Os peixes eram alimentados duas vezes ao dia, 30 min após as coletas, à proporção de $3 \%$ da biomassa. A limpeza das unidades experimentais, para retirada de sobras de ração e resíduos aderidos às paredes do tanque, era feita 30 min após a alimentação, às 9:00 e às 18:00 h. Após a limpeza, aguardava-se o tempo de uma hora, para que as partículas em suspensão se depositassem no fundo do tanque. Assim, antes de recolocar os tubos (10:00 e 19:00 h), descartava-se a água do fundo, o que acontecia abrindo-se o registro por aproximadamente cinco segundos. Os tubos de coleta eram recolocados nos tanques e acondicionados em caixas de poliestireno expandido, com gelo, para minimizar a atividade microbiana. Os tubos eram levados à centrífuga a $145 \mathrm{~g}$ por $5 \mathrm{~min}$, para precipitação das fezes. As fezes coletadas eram armazenadas úmidas em freezer $\left(-18^{\circ} \mathrm{C}\right)$ até o momento das análises e, então, levadas à estufa $\left(60^{\circ} \mathrm{C}\right)$ por 24 horas, para obtenção de amostras parcialmente secas, as quais eram maceradas e homogeneizadas para a realização das análises. 
A concentração de óxido de cromo III foi quantificada pelo método espectrofotométrico da 1,5-difenilcarbazida (Bremer Neto et al., 2005). Os teores de proteína bruta (micro-Kjeldhal) foram determinados de acordo com o método 960.52 da AOAC International (Cuniff, 1995). A matéria seca foi determinada por permanência da amostra em estufa $\left(105^{\circ} \mathrm{C}\right)$ até obtenção de massa constante, e a matéria mineral foi quantificada por queima a $550^{\circ} \mathrm{C}$ pelo método 923.03 da AOAC International (Cuniff, 1995). Todas as determinações foram feitas nas fezes, na dieta-referência e nas dietas-teste.

Tabela 2. Formulação e composição centesimal das dietas utilizadas no experimento de digestibilidade.

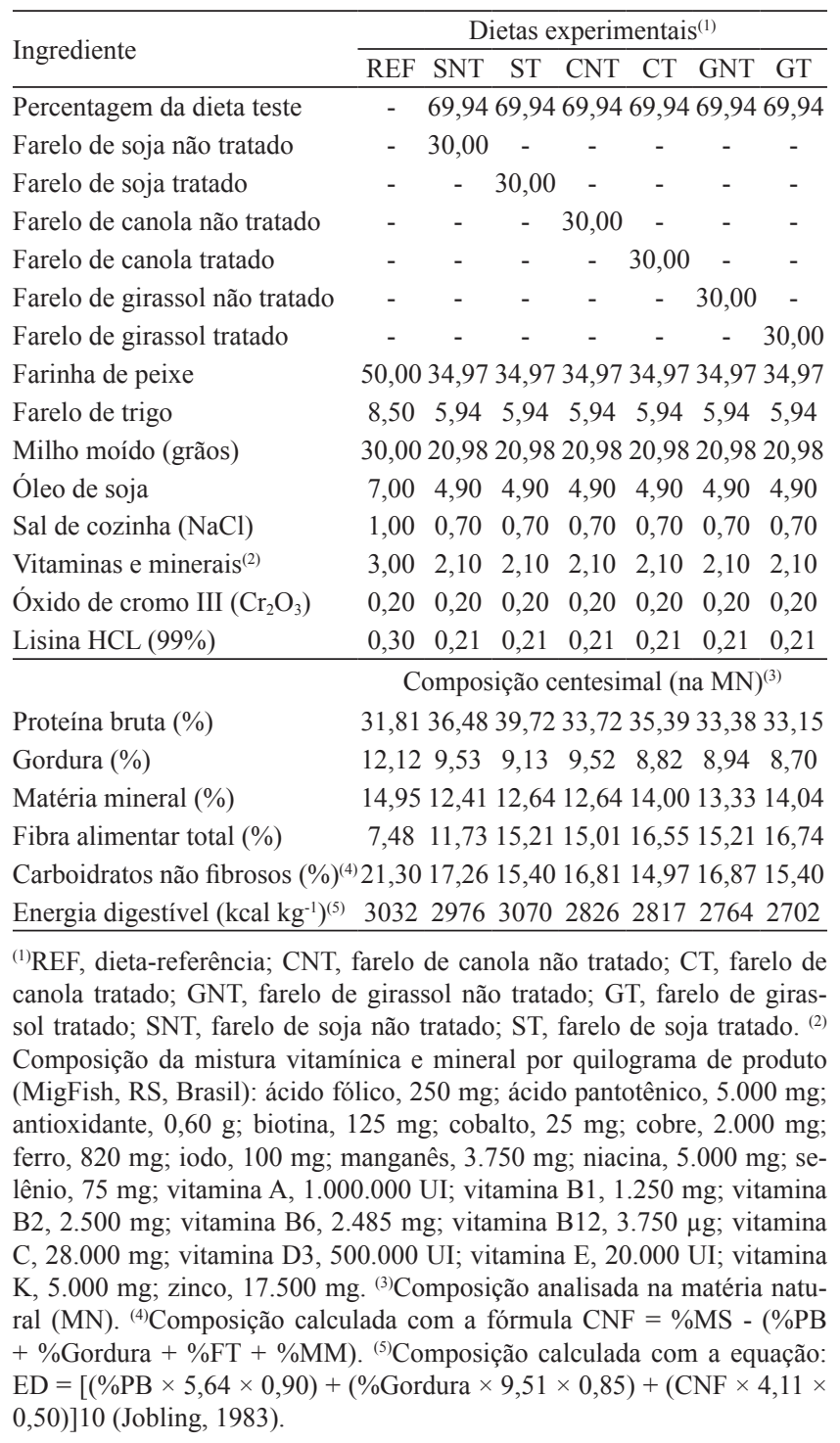

O cálculo do coeficiente de digestibilidade aparente das dietas (CDA) e dos ingredientes (CDAi) foi feito com as seguintes fórmulas, sugeridas por Bureau et al. (1999): CDA $(\%)=100-[100 \times(\mathrm{Id} / \mathrm{If} \times \mathrm{Nf} / \mathrm{Nd})]$ e CDAi $(\%)=\mathrm{CDAdt}+[\mathrm{CDAdt}-\mathrm{CDAref}) \times(\mathrm{r} \times \mathrm{Nref} / \mathrm{i} \times \mathrm{Ni})]$, em que: CDA é o coeficiente de digestibilidade aparente; Id é a concentração de cromo na dieta (\%); If é a concentração de cromo nas fezes (\%); $\mathrm{Nd}$ é a concentração do nutriente na dieta (\%); Nf é a concentração do nutriente nas fezes (\%); CDAi é o coeficiente de digestibilidade aparente do nutriente no ingrediente estudado; CDAdt é o coeficiente de digestibilidade aparente do nutriente na dieta-teste; CDAref é o coeficiente de digestibilidade aparente do nutriente na dieta-referência; $r$ é a proporção da dieta-referência na dieta-teste $(0,6994)$; i é a proporção do ingrediente-teste na dieta-teste $(0,3)$; Nref é a concentração do nutriente na dieta-referência (\% na matéria úmida); Ni é a concentração do nutriente no ingrediente ( $\%$ na matéria úmida).

Os coeficientes de digestibilidade aparente (CDA) da matéria seca, proteína bruta e matéria orgânica dos ingredientes foram submetidos à análise de variância de uma via, com cinco repetições por tratamento (cinco incubadoras). As médias dos CDA foram comparadas pelo teste de Tukey, a 5\% de probabilidade.

\section{Resultados e Discussão}

O tratamento para remoção de antinutrientes foi eficiente na retirada de fenóis totais e taninos totais, nos três farelos avaliados, mas menos eficiente na remoção de ácido fítico (Tabela 1). Para fenóis totais, o valor mínimo de retirada foi de $84 \%$, no farelo de soja, e chegou a $88 \%$ no farelo de girassol. O teor de taninos totais diminuiu em 91\%, no farelo de canola, e em $95 \%$, no farelo de soja. O tratamento reduziu os teores de ácido fítico dos farelos de canola e girassol em 4 e $26 \%$, respectivamente. Contudo, para o farelo de soja, houve aumento de $50 \%$ na concentração deste antinutriente.

Segundo Mwachireya et al. (1999), após o tratamento (lavagem), pode haver perda de outros compostos do farelo, diferentes do que se pretende retirar, como polissacarídeos não amiláceos, carboidratos solúveis, fibra, saponinas e algumas frações da proteína. Assim, mesmo com a possibilidade de se ter retirado uma fração de ácido fítico, o tratamento pode ter diminuído o teor de outros compostos, como os citados, o que 
pode ter ocasionado a concentração do ácido fítico após a lavagem.

Os menores CDA da matéria seca dos tratamentos CNT, CT, GNT e GT, em comparação ao SNT e ST (Tabela 3), podem ser explicados pela maior quantidade de fibra na composição daqueles ingredientes. O CDA da matéria seca permite estimar a quantidade de resíduos excretados e liberados no ambiente, e pode ser utilizado como uma das ferramentas para medir o impacto ambiental da aquicultura (Guimarães et al., 2012). Peixes não secretam celulase, portanto, a digestão da fração fibrosa não tem função importante na obtenção de nutrientes (National Research Council, 2011). Além disso, a fibra influencia a motilidade do alimento no trato digestório, altera a velocidade de passagem do alimento, reduz a digestibilidade dos nutrientes, aumenta a viscosidade da digesta e, consequentemente, reduz o desempenho dos animais (Meurer \& Hayashi, 2003). O aumento da viscosidade intestinal diminui o contato entre as enzimas digestivas e o substrato, aumenta as perdas endógenas de nutrientes e diminui a capacidade de absorção da mucosa, o que provoca menor eficiência na digestão e absorção de nutrientes (Meurer \& Hayashi, 2003; Morgado et al., 2009). Pedron et al. (2008), estudaram fontes e níveis de fibra na alimentação de jundiá, e constataram que dietas com $10 \%$ de fibra bruta prejudicam a digestibilidade da proteína para a espécie. Tal resultado também foi observado no presente estudo, em que os CDA da matéria seca e matéria orgânica foram inferiores nos ingredientes com maior teor de fibra.

Quanto ao CDA da proteína bruta, o tratamento ST foi superior a CT e CNT, mas não diferiu dos demais. Além dos teores de fibra, superiores nos tratamentos CT e CNT, a maior presença de ácido fítico, fenóis totais e taninos nestes farelos pode ter influenciado está resposta. Estes antinutrientes têm a capacidade

Tabela 3. Coeficientes de digestibilidade aparente da matéria seca, proteína bruta e matéria orgânica dos ingredientes avaliados no experimento.

\begin{tabular}{llcc}
\hline \multirow{2}{*}{ Farelo } & \multicolumn{3}{c}{ Coeficiente de digestibilidade aparente (\%) } \\
\cline { 2 - 4 } & Matéria seca & Proteína bruta & Matéria orgânica \\
\hline Canola não tratado & $54,34 \pm 2,57 \mathrm{~d}$ & $82,46 \pm 1,34 \mathrm{~b}$ & $58,79 \pm 1,39 \mathrm{bc}$ \\
Canola tratado & $72,81 \pm 3,93 \mathrm{bc}$ & $83,11 \pm 3,46 \mathrm{~b}$ & $65,62 \pm 3,89 \mathrm{~b}$ \\
Girassol não tratado & $60,90 \pm 1,96 \mathrm{~cd}$ & $88,67 \pm 1,39 \mathrm{ab}$ & $57,08 \pm 1,85 \mathrm{bc}$ \\
Girassol tratados & $62,97 \pm 3,87 \mathrm{~cd}$ & $88,15 \pm 1,11 \mathrm{ab}$ & $53,42 \pm 3,51 \mathrm{c}$ \\
Soja não tratado & $81,32 \pm 2,43 \mathrm{ab}$ & $89,62 \pm 1,29 \mathrm{ab}$ & $79,40 \pm 1,79 \mathrm{a}$ \\
Soja tratado & $87,67 \pm 0,69 \mathrm{a}$ & $94,44 \pm 0,35 \mathrm{a}$ & $81,46 \pm 1,00 \mathrm{a}$ \\
\hline
\end{tabular}

de se ligar direta ou indiretamente a minerais (Ali et al., 2010), reduzir a digestibilidade da proteína e aminoácidos, inibir a atividade de enzimas digestivas e inibir a excreção de nitrogênio fecal em peixes (Bell, 1993; Francis et al., 2001).

Os tratamentos GNT, GT e CNT apresentaram os menores valores de digestibilidade da matéria orgânica. Não houve diferença significativa quanto à digestibilidade da proteína bruta destes ingredientes, em comparação aos tratamentos de melhor resultado para esse nutriente (ST e SNT). Provavelmente, o tratamento para extração de fatores antinutricionais atuou de modo positivo sobre a fração proteína bruta do ingrediente; porém, a alta concentração de fibra pode ter diminuído o coeficiente de digestibilidade das demais frações. Mesmo com alto CDA da proteína, um ingrediente pode ter seu uso limitado pelo baixo aproveitamento de outras frações, o que pode ser observado pelos CDA de matéria seca e matéria orgânica desses ingredientes, nos tratamentos GT e GNT.

O tratamento CT apresentou CDA da matéria seca superior ao do tratamento CNT, e não houve diferença quanto à proteína e à matéria orgânica. $\mathrm{O}$ tratamento para inativação de antinutrientes influenciou a digestibilidade desse ingrediente. A composição do farelo de canola mudou após o tratamento. $O$ teor de carboidratos não fibrosos diminuiu de 6,36 para $0,23 \%$. Estes compostos incluem amido, oligossacarídeos, frutosanas, pectinas, galactanos e $\beta$-glucanos (Morgado et al., 2009), que podem atrapalhar o aproveitamento do alimento pelo aumento da viscosidade intestinal. A redução de teor de carboidratos não fibrosos pode ter contribuído para o melhor aproveitamento de outras frações do ingrediente, como gordura e minerais.

Estudos a respeito do valor nutricional de fontes proteicas de origem vegetal submetidas a tratamentos têm mostrado, consistentemente, melhorias na digestibilidade e crescimento dos peixes, em comparação a fontes não tratadas (Drew et al., 2007). Contudo, as dietas ST e SNT não diferiram entre si em nenhuma das frações avaliadas. Este resultado pode estar relacionado à concentração de ácido fítico nos ingredientes após o tratamento, que foi maior no farelo de soja tratado. Os CDA de GT e GNT também não diferiram entre si. Com estes resultados, confirmam-se os apresentados por Stech et al. (2010), 
que não encontraram diferença significativa entre os coeficientes de digestibilidade aparente da proteína bruta da soja tostada e do farelo de soja para alevinos de pacu (Piaractus mesopotamicus). No entanto, Gonçalves \& Carneiro (2003) observaram diferença significativa, ao comparar a digestibilidade da proteína bruta do farelo de soja, soja processada (tostagem) e soja crua em alevinos de pintado (Pseudoplatystoma coruscans). Os autores atribuem o aumento da eficiência ao processamento experimental, pela destruição dos fatores antinutricionais presentes nesse ingrediente.

Com exceção do CDA da proteína, o farelo de soja apresentou maiores valores de digestibilidade que o de girassol. $\mathrm{O}$ farelo de soja, além da alta disgestibilidade, tem alto teor proteico, bom perfil de aminoácidos e tem seus principais fatores antinutricionais facilmente eliminados durante o processamento (Mohanta et al., 2007).

Os CDA dos farelos não tratados foram semelhantes aos relatados por outros autores, em pesquisa com jundiá (Oliveira Filho \& Fracalossi, 2006) e com outras espécies de bagres de água doce (Kitagima \& Fracalossi, 2011; Guimarães et al., 2012). A única exceção foi observada no CDA da matéria seca do farelo de soja não tratado $(81,32 \%)$, que foi superior aos encontrados pelos autores citados, que obtiveram valores de 51,88 a $74,6 \%$, em Rhamdia quelen e Ictalurus punctatus, respectivamente.

A maior parte dos trabalhos sobre o efeito específico de cada antinutriente foi conduzida com uso de um ingrediente rico em determinado fator antinutricional. Os resultados são atribuídos a este fator, muitas vezes sem considerar outros compostos presentes no ingrediente e a interação entre eles (Francis et al., 2001). Com os dados do presente trabalho, sugerese que os teores de antinutrientes dentro de cada grupo de farelos não foram suficientes para afetar a digestibilidade das frações analisadas. A avaliação de tratamentos para retirada de fatores antinutricionais deve levar em consideração, além da remoção de antinutrientes, a concentração ou remoção de outros compostos, durante o processo, e sua relação com a qualidade nutricional do ingrediente.

\section{Conclusões}

1. O tratamento para remoção de antinutrientes não afeta os coeficientes de digestibilidade da proteína bruta, matéria seca e matéria orgânica dos farelos de soja e girassol.

2. Em farelo de canola, a remoção de fatores antinutricionais melhora a digestibilidade da matéria seca.

\section{Agradecimentos}

À Universidade Federal de Santa Maria (UFSM), à Coordenação de Aperfeiçoamento de Pessoal de Nível Superior (Capes), ao Conselho Nacional de Desenvolvimento Científico e Tecnológico (CNPq), e à Fundação de Amparo à Pesquisa do Estado do Rio Grande do Sul (Fapergs), por bolsas concedidas; e ao CNPq e Ministério da Pesca e Aquicultura, pelo apoio financeiro.

\section{Referências}

ALI, M.; SHUJA, M.N.; ZAHOOR, M.; QADRI, I. Phytic acid: how far have we come? African Journal of Biotechnology, v.9, p.1551-1554, 2010.

BALDISSEROTTO, B.; SILVA, L.V.F. Qualidade da água. In: BALDISSEROTTO, B.; RADÜNZ NETO, J. (Ed.). Criação de jundiá. Santa Maria: Universidade Federal de Santa Maria, 2005. p.73-92.

BELL, J.M. Factors affecting the nutritional value of canola meal: a review. Canadian Journal of Animal Science, v.73, p.679-697, 1993. DOI: $10.4141 /$ cjas93-075.

BREMER NETO, H.; GRANER, C.A.F.; PEZZATO, L.E.; PADOVANI, C.R. Determinação de rotina do crômio em fezes, como marcador biológico, pelo método espectrofotométrico ajustado da 1,5-difenilcarbazida. Ciência Rural, v.35, p.691-697, 2005. DOI: 10.1590/S0103-84782005000300033.

BUREAU, D.P.; HARRIS, A.M.; CHO, C.Y. Apparent digestibility of rendered animal protein ingredients for rainbow trout (Oncorhynchus mykiss). Aquaculture, v.180, p.345-358, 1999. DOI: 10.1016/S0044-8486(99)00210-0.

CHO, C.Y.; BUREAU, D.P. A review of diet formulation strategies and feeding systems to reduce excretory and feed wastes in aquaculture. Aquaculture Research, v.32, p.349-360, 2001. DOI: 10.1046/j.1355-557x.2001.00027.x.

CHO, C.Y.; COWEY, C.B.; WATANABE, T. Finfish nutrition in Asia: methodological approaches to research and development. Ottawa: International Development Research Center, 1985. 154p.

COLDEBELLA, I.J.; RADÜNZ NETO, J. Farelo de soja na alimentação de alevinos de jundiá (Rhamdia quelen). Ciência Rural, v.32, p.499-503, 2002. DOI: 10.1590/ S0103-84782002000300021.

CUNIFF, P. (Ed.). Official methods of analysis of AOAC International. $16^{\text {th }}$ ed. Gaithersburg: AOAC International, 1995. 2v. 
DREW, M.D.; BORGESON, T.L.; THIESSEN, D.L. A review of processing of feed ingredients to enhance diet digestibility in finfish. Animal Feed Science and Technology, v.138, p.118-136, 2007. DOI: $10.1016 /$ j.anifeedsci.2007.06.019.

FRANCIS, G.; MAKKAR, H.P.S.; BECKER, K. Antinutritional factors present in plant-derived alternate fish feed ingredients and their effects in fish. Aquaculture, v.199, p.197-227, 2001. DOI: 10.1016/S0044-8486(01)00526-9.

GATLIN III, D.M.; BARROWS, F.T.; BROWN, P.; DABROWSKI, K.; GAYLORD, T.G.; HARDY, R.W.; HERMAN, E.; HU, G.; KROGDAHL, Å.; NELSON, R.; OVERTURF, K.; RUST, M.; SEALEY, W.; SKONBERG, D.; SOUZA, E.J.; STONE, D.; WILSON, R.; WURTELE, E. Expanding the utilization of sustainable plant products in aquafeeds: a review. Aquaculture Research, v.38, p.551-579, 2007. DOI:10.1111/ j.1365-2109.2007.01704.x.

GONÇALVES, E.G.; CARNEIRO, D.J. Coeficientes de digestibilidade aparente da proteína e energia de alguns ingredientes utilizados em dietas para o pintado (Pseudoplatystoma coruscans). Revista Brasileira de Zootecnia, v.32, p.779-786, 2003. DOI: 10.1590/S1516-35982003000400001.

GUIMARÃES, I.G.; PEZZATO, L.E.; BARROS, M.M.; FERNANDES, R. do N. Apparent nutrient digestibility and mineral availability of protein-rich ingredients in extruded diets for Nile tilapia. Revista Brasileira de Zootecnia, v.41, p.1801-1808, 2012. DOI: 10.1590/S1516-35982012000800001.

JOBLING, M. A short review and critique of methodology used in fish growth and nutrition studies. Journal of Fish Biology, v.23, p.685-703, 1983. DOI: 10.1111/j.1095-8649.1983.tb02946.x.

KAUSHIK, S.J.; SEILIEZ, I. Protein and amino acid nutrition and metabolism in fish: current knowledge and future needs. Aquaculture Research, v.41, p.322-332, 2010. DOI: 10.1111/j.1 365-2109.2009.02174.x.

KITAGIMA, R.E.; FRACALOSSI, D.M. Digestibility of alternative protein-rich feedstuffs for channel catfish, Ictalurus punctatus. Journal of the World Aquaculture Society, v.42, p.306-312, 2011. DOI: 10.1111/j.1749-7345.2011.00468.x.

LAZZARI, R.; RADÜNZ NETO, J.; PEDRON, F.A.; VEIVERBERG, C.A.; BERGAMIN, G.T.; LIMA, R.L.; EMANUELLI, T.; STEFFENS, C. Desempenho e composição dos filés de jundiás (Rhamdia quelen) submetidos a diferentes dietas na fase de recria. Arquivo Brasileiro de Medicina Veterinária e Zootecnia, v.60, p.477-484, 2008. DOI: 10.1590/ S0102-09352008000200030.

MEURER, F.; HAYASHI, C. Polissacarídeos não amiláceos na nutrição de peixes - revisão. Arquivos de Ciências Veterinárias e Zoologia da UNIPAR, v.6, p.127-138, 2003.

MOHANTA, K.N.; MOHANTY, S.N.; JENA, J.; SAHU, N.P. Effect of different oil cake sources on growth, nutrient retention and digestibility, muscle nucleic acid content, gut enzyme activities and whole-body composition in silver barb, Puntius gonionotus fingerlings. Aquaculture Research, v.38, p.1702-1713, 2007.

MORGADO, E. da S.; ALMEIDA, F.Q. de; SILVA, V.P.; GOMES, A.V. da C.; GALZERANO, L.; VENTURA, H.T.; RODRIGUES, L.M. Digestão dos carboidratos de alimentos volumosos em equinos. Revista Brasileira de Zootecnia, v.38, p.75-81, 2009. DOI: 10.1590/S1516-35982009000100010.

MWACHIREYA, S.A.; BEAMES, R.M.; HIGGS, D.A.; DOSANJH, B.S. Digestibility of canola protein products derived from the physical, enzymatic and chemical processing of commercial canola meal in rainbow trout Oncorhynchus mykiss (Walbaum) held in fresh water. Aquaculture Nutrition, v.5, p.73-82, 1999. DOI: 10.1046/j.1365-2095.1999.00089.x.

NATIONAL RESEARCH COUNCIL. Nutrient requeriments of fish and shrimp. Washington: National Academy, 2011. 376p.

NAYLOR, R.L.; GOLDBURG, R.J.; PRIMAVERA, J.H.; KAUTSKY, N.; BEVERIDGE, M.C.M.; CLAY, J.; FOLKE, C.; LUBCHENCO, J.; MOONEY, H.; TROELL, M. Effect of aquaculture on world fish supplies. Nature, v.405, p.1017-1024, 2000. DOI:10.1038/35016500.

OLIVEIRA FILHO, P.R.C.; FRACALOSSI, D.M. Coeficientes de digestibilidade aparente de ingredientes para juvenis de jundiá. Revista Brasileira de Zootecnia, v.35, p.1581-1587, 2006. DOI: 10.1590/S1516-35982006000600002.

ORGANIZACIÓN DE LAS NACIONES UNIDAS PARA LA AGRICULTURA Y LA ALIMENTACIÓN. EI estado mundial de la pesca y la acuicultura. 2012. Disponible en: $<$ http://www. fao.org/docrep/016/i2727s/i2727s00.htm>. Acceso el: 11 set 2012.

PEDRON, F. de A.; RADÜNZ NETO, J.; EMANUELLI, T.; SILVA, L.P. da; LAZZARI, R.; CORRÊIA, V.; BERGAMIN, G.T.; VEIVERBERG, C.A. Cultivo de jundiás alimentados com dietas com casca de soja ou de algodão. Pesquisa Agropecuária Brasileira, v.43, p.93-98, 2008. DOI: 10.1590/ S0100-204X2008000100012.

SILVA, P.R.F. da; FREITAS, T.F.S. de. Biodiesel: o ônus e o bônus de produzir combustível. Ciência Rural, v.38, p.843-851, 2008. DOI: $10.1590 / \mathrm{S} 0103-84782008000300044$.

STECH, M.R.; CARNEIRO, D.J.; CARVALHO, M.R.B. de. Fatores antinutricionais e coeficiente de digestibilidade aparente da proteína de produtos de soja para o pacu(Piaractus mesopotamicus). Acta Scientiarum. Animal Sciences, v.32, p.255-262, 2010. DOI: 10.4025/actascianimsci.v32i3.5819.

VAN SOEST, P.J. Development of a comprehensive system of feed analysis and its application to forage. Journal of Animal Science, v.26, p.119-120, 1967.

Recebido em 21 de janeiro de 2013 e aprovado em 7 de junho de 2013

Pesq. agropec. bras., Brasília, v.48, n.8, p.928-934, ago. 2013

DOI: $10.1590 / \mathrm{S} 0100-204 X 2013000800017$ 